\title{
Unpacking the construct of emotional attachment to objects and its association with hoarding symptoms
}

\author{
KEONG $\mathrm{YAP}^{1,2 *}$ and JESSICA R. GRISHAM ${ }^{1}$ \\ ${ }^{1}$ School of Psychology, University of New South Wales, Sydney, NSW, Australia \\ ${ }^{2}$ School of Behavioural and Health Sciences, Australian Catholic University, Strathfield, NSW, Australia
}

(Received: August 25, 2018; revised manuscript received: February 9, 2019; accepted: March 15, 2019)

\begin{abstract}
Background and aims: The appetitive aspects of hoarding disorder, such as the compulsive acquisition and saving of objects, are akin to other behavioral addictions. Underpinning these appetitive features is the strong emotional and sentimental attachments that hoarding sufferers have for their possessions. Different facets of object attachment have been identified including anthropomorphism, insecure object attachment, possessions as an extension of identity, possessions as a repository of autobiographical memories, and possessions as a source of comfort and safety. The aim of this study was to examine the association between each of these facets and hoarding symptoms independent of non-sentimental hoarding beliefs, depression, and anxiety. Methods: Participants were 532 individuals recruited via Turkprime who completed online self-report questionnaires on hoarding symptoms, hoarding beliefs, depression, anxiety, and the facets of object attachment. Pearson's correlations and hierarchical multiple regression analyses were conducted. Results: The results showed that all facets of object attachment were positively correlated with hoarding symptoms. After accounting for other non-sentimental hoarding beliefs, depression, and anxiety, three facets made significant unique contributions to hoarding symptoms: insecure object attachment, anthropomorphism, and possessions as a repository of autobiographical memories. Discussion and conclusions: Based on these findings, we propose a compensatory model to explain how the different facets of object attachment may be implicated in hoarding. Further research into ways of reducing anthropomorphism, insecure object attachment, and possessions as memories are warranted.
\end{abstract}

Keywords: anthropomorphism, emotional attachment to objects, hoarding, hoarding disorder, insecure object attachment, object attachment

\section{INTRODUCTION}

Hoarding disorder (HD) is characterized by the need to save possessions and strong emotional distress when discarding items regardless of their actual value. HD results in the accumulation of an excessive and disorganized amount of possessions in the home, so that living areas are cluttered and unusable (American Psychiatric Association [APA], 2013). Although categorized as related to obsessivecompulsive disorder (OCD) in the fifth edition of Diagnostic and Statistical Manual of Mental Disorders (APA, 2013), the appetitive aspects of $\mathrm{HD}$, including compulsive acquisition and the experience of pleasure and desire toward inanimate objects, are more akin to behavioral addictions. (Grisham, Williams, \& Kadib, 2010).

Associated with the appetitive aspects of HD is the strong emotional attachment to objects (or object attachment). Object attachment is defined as an "affect-laden possession-specific bond between a person and an object or objects" (Kellett \& Holden, 2014, p. 2) and encompasses both positive and negative emotions (e.g., feelings of responsibility, sentimentality, affection, pleasure, and comfort) to a wide and indiscriminate range objects (Grisham et al., 2009; Mogan, Kyrios,
Schweitzer, Yap, \& Moulding, 2012). Although it is a central feature of cognitive-behavioral models of HD (Kyrios et al., 2018), our current understanding of this phenomenon is limited. Various facets of object attachment, such as insecure object attachment (IOA), anthropomorphism, the use of objects as extensions of the self, and the use of possessions for comfort and safety, have been identified, but these facets are also common in normal populations (Csikszentmihalyi \& Rochberg-Halton, 1981; Furby, 1978; Miller, 2008). Furthermore, although non-sentimental beliefs, such as the need for control over possessions, feelings of responsibility for possessions, and the belief that objects are important as memory aids, are known to drive hoarding, these beliefs are also highly correlated with object attachment (Frost et al., 2018; Steketee, Frost, \& Kyrios, 2003). Thus, it is unclear if the impact of object attachment facets is independent of these non-sentimental hoarding beliefs.

\footnotetext{
* Corresponding author: Keong Yap; School of Behavioural and Health Sciences, Australian Catholic University, 25A Barker Road, Strathfield, NSW 2035, Australia; Phone: +612 9701 4574; E-mail: Keong.yap@acu.edu.au
}

This is an open-access article distributed under the terms of the Creative Commons Attribution-NonCommercial 4.0 International License, which permits unrestricted use, distribution, and reproduction in any medium for non-commercial purposes, provided the original author and source are credited, a link to the CC License is provided, and changes - if any - are indicated. 
As object attachment is reported as one of the main reasons given by HD patients for the excessive saving of items (Frost, Steketee, Tolin, Sinopoli, \& Ruby, 2015; Pertusa et al., 2008), it is important to address these gaps in our understanding in order to inform improvements to HD treatment.

\section{Object attachment in $H D$}

Hoarding was initially considered as a symptom of obsessivecompulsive personality disorder in which the individual is "unable to discard worn-out or worthless objects even when they have no sentimental value" (APA, 2000, p. 729). This is however inconsistent with Frost and Hartl's (1996) early observations; they noted that individuals with compulsive hoarding often had a hypersentimentality to possessions such that "possessions were seen as a part of the self and getting rid of them was like losing a close friend. They served as meaningful reminders of important past events." (p. 347). Frost and Hartl also reported that for many of these individuals, possessions were valued as a source of comfort and security, and were used to manage stress and other difficult emotions.

These observations are supported by studies reporting positive correlations between object attachment and hoarding symptoms in non-clinical and clinical samples (Frost, Hartl, Christian, \& Williams, 1995; Grisham et al., 2009; Kyrios et al., 2018). In addition, individuals with compulsive hoarding have reported significantly higher object attachment compared to non-clinical and clinical controls (Grisham, Steketee, \& Frost, 2008; Steketee et al., 2003), indicating that high object attachment might be specific to HD.

In contrast with these findings, Steketee et al. (2003) found that object attachment did not uniquely predict hoarding symptoms after accounting for age, depression, anxiety, and other hoarding and OCD-related beliefs, indicating that the relationship between object attachment and hoarding symptoms might be better explained by its association with other hoarding beliefs, such as a need for control, feelings of responsibility, and beliefs about memory. However, Steketee et al. used the Saving Cognitions Inventory - Emotional Attachment subscale (SCI-EA), which conflates the different facets of object attachment. For example, the SCI-EA has items tapping into the use of possessions for comfort - "This possession provides me with emotional comfort," anthropomorphic tendencies - "Losing this possession is like losing a friend," and objects as extensions of the self - "Throwing away this possession is like throwing away a part of me." Thus, several researchers have urged further research into the separate facets of object attachment (Kellett \& Holden, 2014; Kings, Moulding, \& Knight, 2017).

\section{Possessions for comfort and safety}

The use of objects as a source of comfort is not unusual, and has been observed in children who use inanimate objects as transitional objects (Fortuna, Baor, Israel, Abadi, \& Knafo, 2014; Winnicott, 1953) and among adults particularly to induce positive memories and moods (Csikszentmihalyi \& Rochberg-Halton, 1981). However, it appears that this tendency to rely on objects for comfort is substantially higher in individuals with compulsive hoarding (Hartl, Duffany, Allen, Steketee, \& Frost, 2005; Nedelisky \& Steele, 2009) and might be an attempt by sufferers to cope with past trauma, especially interpersonal trauma (Cromer, Schmidt, \& Murphy, 2007; Hartl et al., 2005; Przeworski, Cain, \& Dunbeck, 2014).

Paradoxically, although people with hoarding problems might overuse objects for comfort and safety, they also feel more anxious about their possessions than people who do not hoard (Nedelisky \& Steele, 2009). This could be due to the lack of trust in other people's respect for their possessions and the fear that belongings would be discarded without consent especially in forced clean-outs. Thus, a maladaptive feedback loop might develop, in which past neglect or trauma leads to anxiety and insecurity, which then triggers the gathering of possessions to soothe distress. This feeds further stress and anxiety because of both the anxiety over losing one's possessions and the negative ramifications of the resulting clutter, such as attention from housing authorities and health departments (Bratiotis et al., 2013).

This insecure attachment to objects might be in part due to the tendency in people with compulsive hoarding problems to imbue objects with human-like qualities and to consider possessions as a part of themselves; the object becomes not just something but also someone, not just mine but also me (Frost et al., 1995; Kellett, Greenhalgh, Beail, \& Ridgway, 2010). Losing such possessions might thus have greater negative consequences because it equates the loss of self or a significant other.

\section{Anthropomorphism and possessions as self-extensions}

Defined as "perceiving humanlike characteristics in either real or imagined nonhuman agents" (Epley, Waytz, Akalis, \& Cacioppo, 2008, p. 144), anthropomorphism is a common phenomenon that many people experience to varying degrees. To date, a few studies have reported significant positive associations between anthropomorphism and hoarding symptoms (Neave, Jackson, Saxton, \& Hönekopp, 2015; Neave, Tyson, McInnes, \& Hamilton, 2016; Norberg, Crone, Kwok, \& Grisham, 2018; Timpano \& Shaw, 2013). Timpano and Shaw (2013) also showed that anthropomorphism increased the strength of association between hoarding beliefs and emotional attachment to novel items.

Similar to anthropomorphism, the use of possessions as self-extensions is a major function of treasured possessions for most people and has also been reported in several qualitative studies with HD participants (Kellett et al., 2010; Kings, Knight, \& Moulding, 2018; Roster, 2015). The only quantitative study in this area on HD was conducted by Dozier, Taylor, Castriotta, Mayes, and Ayers (2017). They showed that individuals with HD reported a significantly higher overlap between their sense of self and personal possessions (object interconnectedness) compared to community controls, and that object interconnectedness in the hoarding group was positively and moderately correlated with difficulties discarding.

Another neglected facet of the use of possessions as selfextensions is the reliance on objects to trigger autobiographical memories. For many people, certain objects attain meaning because of their links with important memories 
of significant events and people. As noted by Conway, Singer, and Tagini (2004), autobiographical memories are required for the construction of the self and its coherence. The use of objects as a repository of autobiographical memories is thus intriguing because such externalization of the autobiographical self provides opportunities to selectively reinforce the self, not only through rehearsal and ongoing meaning making (Wang, Lee, \& Hou, 2017), but also through public displays of the self - like badges of one's accomplishments.

For individuals who hoard, the need to retain an excessively large number of possessions might similarly be in the service of bolstering the autobiographical self, but it would probably be counterproductive because these objective cues to memories are excessive, without focus and thus risks a breakdown in coherence. Although the use of objects to bolster the autobiographical self in HD has been qualitatively reported (Cherrier \& Ponnor, 2010), no empirical investigation has been conducted.

\section{Aims and hypotheses}

The aim of this study is to extend the cognitive-behavioral therapy model of hoarding by elaborating on the role that object attachment plays in hoarding symptoms. Aspects of object attachment identified include the tendency to look into possessions for comfort and safety (Frost et al., 1995; Hartl et al., 2005), IOA (Nedelisky \& Steele, 2009), anthropomorphism (Neave et al., 2016; Timpano \& Shaw, 2013), the use of possessions as self-extensions (Dozier et al., 2017), and the use of possessions for the preservation of autobiographical memories (Cherrier \& Ponnor, 2010). These facets are, however, not unique to individuals who hoard and therefore one or more of them may not be significantly associated with hoarding symptoms. Furthermore, it is unclear whether these constructs predict hoarding symptoms over and above other hoarding beliefs and general psychological distress.

We hypothesized that the following facets of object attachment would be significantly and positively associated with the hoarding symptoms: (a) IOA, (b) anthropomorphism, (c) the tendency to use possessions to preserve autobiographical memories, (d) the tendency to use possessions as identity, and (e) the tendency to use possessions for comfort and safety. We also hypothesized that each of these facets would make unique contributions to variability in hoarding symptoms (clutter, acquisition, and difficulties discarding) in a community sample, and that these would remain significant even after accounting for depression, anxiety, and other hoarding beliefs.

\section{METHODS}

\section{Participants}

Participants were 532 adults (244 males and 288 females) aged 18-81 years (mean age $=36.2$ years, $S D=10.6$ ). Most of them were white $(72.9 \%), 11.8 \%$ were AfricanAmerican, and the remaining $15.3 \%$ identified as Asian, American Indian, or other. Participants were recruited through Turkprime (www.turkprime.com), which is an online crowdsourcing service designed for social science research. It coordinates and sources individuals using Amazon's Mechanical Turk (MTurk; http://www.mturk.com) to perform computerized tasks such as completion of online surveys. MTurk is widely used in psychological research and the reliability and validity of MTurk data have been supported in several studies (Chandler \& Shapiro, 2016).

The use of Turkprime and MTurk workers (who completed the surveys for a small monetary compensation) provided a sample with a broad range of object attachment and hoarding symptoms. The use of non-clinical samples to examine HD is justified, given the similarities in psychological processes between clinical and analogue samples (Coles, Frost, Heimberg, \& Steketee, 2003). In the current sample, 102 participants (19.2\%) scored higher than the recommended clinical cut-off score of $\geq 41$ on the Saving Inventory - Revised (SI-R; Frost \& Hristova, 2011; Frost, Steketee, \& Grisham, 2004). This relatively high percentage of possible HD in our sample is not surprising, given that the prevalence of psychological disorders among MTurk workers is somewhat higher than in the general population (Arditte, Çek, Shaw, \& Timpano, 2016). This might be due to MTurk surveys being more accessible and acceptable to individuals who are introverted or have relatively lower levels of self-esteem (Chandler \& Shapiro, 2016).

Recruitment was restricted to North American MTurk workers with at least $95 \%$ MTurk approval ratings. Of the 658 participants who commenced the online survey, 126 participants were excluded from the study due to failure to complete the survey $(n=51)$, completing the survey in less than $15 \mathrm{~min}(n=50)$, failure to respond correctly to two check items, e.g., "please respond 7, strongly agree on this item" ( $n=17)$, self-declaration that their responses were not valid $(n=7)$, and invariance in responses on the first page of the SI-R, which had reverse scored items $(n=1)$.

\section{Materials and procedure}

Following ethics approval, the participants were recruited through Turkprime and were paid US\$4 for completion of the study. Self-report measures were administered using an online survey interface (www.qualtrics.com) and are described below.

The SI-R (Frost et al., 2004) is a 23-item self-report measure of compulsive hoarding, comprising three subscales: acquisition, difficulty discarding, and clutter. The participants are asked about their experiences over the past week and items are rated on a 5-point Likert scale from 0 (none/not at all/never) to 4 (almost all or completelextreme/ very often). The SI-R has excellent psychometric properties (Frost et al., 2004). The total and subscale scores have very good internal consistency reliability in this study ( $\alpha$ ranging from .77 to .95 ; Table 1$)$.

The SCI (Steketee et al., 2003) is a 24-item self-report measure of beliefs associated with hoarding. It has four subscales: emotional attachment (SCI-EA), control, memory, and responsibility. The items are a list of hoardingrelated thoughts, and participants are asked to indicate the extent to which they had each thought when deciding whether to throw something away during the past week on a 7-point Likert scale from 1 (not at all) to 7 (very much). 
Table 1. Means and standard deviations $(S D \mathrm{~s})$ for all variables $(N=532)$

\begin{tabular}{lrrc}
\hline Variable & Mean & \multicolumn{1}{c}{$S D$} & Cronbach's $\alpha$ \\
\hline SI-R-total & 25.67 & 16.03 & .96 \\
SI-R-acq & 7.94 & 4.98 & .86 \\
SI-R-clutter & 7.96 & 7.19 & .94 \\
SI-R-discard & 9.80 & 5.70 & .90 \\
DASS-dep & 10.70 & 11.75 & .94 \\
DASS-anx & 6.36 & 7.19 & .86 \\
SCI-EA & 26.99 & 13.91 & .95 \\
SCI-mem & 12.74 & 6.61 & .85 \\
SCI-ctr & 12.73 & 5.17 & .77 \\
SCI-resp & 17.11 & 8.31 & .86 \\
RAQ-IOAS & 35.60 & 12.92 & .91 \\
AQcurrent & 7.84 & 10.08 & .90 \\
PAM & 25.09 & 8.78 & .91 \\
PAI & 23.75 & 11.76 & .93 \\
PCS & 93.79 & 42.38 & .97 \\
\hline
\end{tabular}

Note. Means and SDs were calculated from winsorized data. SI-R: Saving Inventory - Revised; SI-R-acq: Saving Inventory - Revised Excessive Acquisition subscale; SI-R-clutter: Clutter subscale, SI-R-discard: Difficulty Discarding subscale; DASS-dep: Depression subscale; DASS-anx: Anxiety subscale; SCI-EA: Saving Cognitions Inventory Emotional Attachment subscale; SCI-mem: Memory subscale; SCI-ctr: Control subscale; SCI-resp: Responsibility subscale; RAQ-IOAS: Reciprocal Attachment Questionnaire Adjusted Inanimate Object Attachment Security; AQcurrent: Anthropomorphism Questionnaire - Current Subscale; PAM: Possessions as Memory Scale; PAI: Possessions as Identity Scale; PCS: Possessions Comfort Scale.

The subscales have excellent psychometric properties (Steketee et al., 2003) and good internal consistency reliabilities in this study ( $\alpha$ ranging from .77 to .95).

The 21 item Depression Anxiety Stress Scales (DASS-21; Lovibond \& Lovibond, 1995) is a 21-item measure of psychological distress and comprises three 7-item subscales: depression, anxiety, and stress. Participants are asked to rate how they have been feeling for the past week on a 4-point scale from 0 (never) to 3 (always). The DASS-21 has excellent psychometric properties (Brown, Chorpita, Korotitsch, \& Barlow, 1997). The depression and anxiety subscales used in this study have very good internal consistency reliability ( $\alpha=.94$ and .86 , respectively).

The Anthropomorphism Questionnaire - Current (AQcurrent; Neave et al., 2015) is a 10-item measure of adult beliefs and behaviors about anthropomorphism. Participants are asked to indicate the extent to which you agree with the items on a 7-point Likert scale from 0 (not at all) to 6 (very much so). The AQcurrent has excellent psychometric properties and excellent internal consistency reliability in this study $(\alpha=.90)$.

The Possessions Comfort Scale (PCS; Hartl et al., 2005) is a 32-item measure of the extent to which people consider their possessions as sources of comfort, safety, and security. Participants are asked about the extent to which they agree or disagree on a 7-point Likert scale from 1 (strongly disagree) to 7 (strongly agree). The PCS has very good psychometric properties (Hartl et al., 2005) and excellent internal consistency reliability in this study $(\alpha=.97)$.
The Possessions as Memories and Self-Extensions Scale (Yap \& Grisham, 2018) is a 14-item measure of the extent to which people consider their possessions as an extension of their identity. It has two subscales: the 6-item Possessions as Memory subscale (PAM) measures the extent to which objects represent personal autobiographical memories of people and events in the past and the 8-item Possessions as Identity subscale (PAI) measures the extent to which objects signify who they are and who they would like to be. Participants are asked about the extent to which they agree or disagree on a 7-point Likert scale from 1 (strongly disagree) to 7 (strongly agree). The PAI and PAM have very good psychometric properties (Yap \& Grisham, 2018) and excellent internal consistency reliability in this study $(\alpha=.91$ and .93 , respectively).

The 17-item inanimate object attachment security subscale from the Reciprocal Attachment Questionnaire Adjusted (Nedelisky \& Steele, 2009) is a measure of IOA. Participants are asked to rate the extent to which they agree with the items on a 5-point Likert scale from 1 (disagree) to 5 (agree); higher scores indicate an insecure attachment to objects. The subscale has good psychometric properties (Nedelisky \& Steele, 2009) and excellent internal consistency reliability in this study $(\alpha=.91)$.

\section{Analytical strategy}

Zero-order Pearson's correlations were calculated to examine the relationship between hoarding symptoms and all facets of object attachment. In four separate multiple regression analyses, the unique contributions of these facets were evaluated, with the total SI-R score and subscales of the SI-R as dependent variables. The Reciprocal Attachment Questionnaire - Inanimate Object Attachment (RAQ-IOAS), AQcurrent, PAM, PAI, and PCS were entered as the predictor variables. DASS depression, DASS anxiety, SCI-memory, SCI-control, and SCI-responsibility were first entered to examine the contribution of the proposed variables after accounting for these covariates. The SCI-EA was not included as a covariate due to its overlap with the facets of object attachment.

\section{Ethics}

The study procedures were carried out in accordance with the Declaration of Helsinki and were approved by the University of New South Wales prior to commencement of data collection. All participants provided informed consent and were free to withdraw consent and to discontinue participation at any time without prejudice.

\section{RESULTS}

\section{Preliminary analyses}

Table 1 shows means, standard deviations, and range of study variables. The RAQ-IOAS, PAM, and PAI were normally distributed. The distributions for SI-R and its subscales, SCI subscales, AQcurrent, PCS, DASS-depression, and DASSanxiety, were positively skewed. A small number of 
univariate statistical outliers $( \pm 3 S D$ from the mean) were detected ( $\leq 10$ per variable) and winsorized prior to analyses. Following windsorizing, the positive skewness persisted for SI-R-clutter, DASS-depression, DASS-anxiety, and AQcurrent. $\log 10(\mathrm{x}+1)$ transformations corrected for skewness of these variables and were used in all subsequent analyses. There were no significant differences between genders on SI-R-total or subscale scores.

Given that transformations were used, care should be taken when interpreting results about the percentage of change in dependent variables per unit of increase in the transformed predictors. Given that the aim of the study does not involve such interpretations, the use of transformations was deemed appropriate.

\section{Correlational analyses}

Table 2 shows zero-order Pearson's correlations among all variables. As predicted, all aspects of object attachment had moderate to strong positive correlations with hoarding symptoms ( $r$ ranged from .32 to .59 ). There was a weak correlation between age and SI-R-acquisition $(r=.09$, $p=.04$ ) but age was not significantly correlated with SI-R-total, clutter, and discard. As such, age was included as a covariate in the regression model for SI-R-acquisition. There were very high correlations between PCS and RAQ-IOAS $(r=.75, p<.0001)$ and between PCS and PAI $(r=.82, p<.0001)$.

\section{Hierarchical multiple regression analyses}

Hierarchical multiple regression analyses were conducted with SI-R-total and its subscales as dependent variables. Log10-Transformed DASS-depression and -anxiety subscales, and the SCI-memory, control, and responsibility subscales were entered in Step 1. Age was included as an additional covariate for SI-R-acquisition. RAQ-IOAS, $\log 10$-transformed AQcurrent, PAM, PAI, and PCS were entered in Step 2. Assumptions of homoscedasticity and multivariate normality were met. Multicollinearity diagnostics were in the acceptable range (variance inflation factor $<5$ ). Across all regression analyses, four multivariate outliers were detected using Mahalonobis distances with a cut-off at $p<.001$. No errors in data entry were detected, and as outliers are not unexpected with large sample sizes, these participants were retained in all analyses.

The results showed that the facets of object attachment as a whole significantly predicted hoarding symptoms (SI-R-total and all subscales) even after accounting for depression, anxiety, and hoarding beliefs. RAQ-IOAS consistently made unique contributions to all hoarding symptoms (SI-R-total and subscales). AQcurrent (anthropomorphism) made unique contributions to the SI-R compulsive acquisition and clutter. PAM made a unique contribution to the SI-R difficulty discarding subscale (Tables 3-6).

\section{DISCUSSION}

The results partially supported our hypotheses. Moderate to strong positive correlations were found between all aspects of object attachment and hoarding symptoms. However, only some of the facets made significant unique contributions to hoarding symptoms after accounting for depression, anxiety, and non-sentimental hoarding beliefs. Specifically, after controlling for these variables, IOA stood out as the facet that made unique contributions to overall hoarding severity, compulsive acquisition, clutter, and difficulty discarding. Anthropomorphism contributed significantly and uniquely to compulsive acquisition and clutter, whereas the use of possessions to preserve autobiographical memory contributed significantly to difficulties discarding.

The current findings are consistent with previous research showing positive associations between facets of object attachment and hoarding symptoms (Kellett \& Holden, 2014) and extend these findings by demonstrating that certain facets predict hoarding symptoms even after accounting for depression, anxiety, and other non-sentimental hoarding beliefs. Although insecure object attachment (IOA) is not explicitly mentioned in the cognitive behavioral model of HD, the finding that IOA was the most consistent predictor of hoarding symptoms does not contradict the cognitive-behavioral model. IOA might interact with information processing difficulties and could explain why individuals with HD have a strong need to control their possessions and to have their possessions in view (Kyrios et al., 2018).

The finding that the use of possessions for autobiographical memories was a significant unique contributor to the SI-R-discard subscale indicates that the imbuing of value to an object through its links with autobiographical memories is a significant barrier to discarding and deserves further research. Furthermore, even though the facet had a strong positive correlation with SCI-memory, it remained a unique contributor to the SI-R-difficulty discarding subscale, confirming that it reflects more than just short-term memory concerns.

Finally, the finding that anthropomorphism contributed significantly to compulsive acquisition and clutter is also consistent with previous research. For example, Burgess, Graves, and Frost (2018) and Neave et al. (2015) found moderate to strong correlations between hoarding behaviors and different measures of anthropomorphism. Of note, Norberg et al. (2018) found that among individuals with high levels of acquiring problems, anthropomorphic tendencies mediated the association between anxious attachment and compulsive acquisition. These findings, together with the results of this study, indicate that understanding and dealing with anthropomorphism is a priority in HD treatment.

However, our findings were partially inconsistent with Steketee et al. (2003) who found that object attachment was not a significant predictor of hoarding symptoms after accounting for age, depression, anxiety, hoarding, and OCD beliefs. One explanation is that Steketee et al. also controlled for OCD symptoms and indecisiveness and these factors might have been responsible for the accounted variance. Another explanation is that their measure of object attachment (SCI-EA) had items measuring self-extension, anthropomorphism, and possessions as comfort but did not include items that measured IOA and the use of possessions 


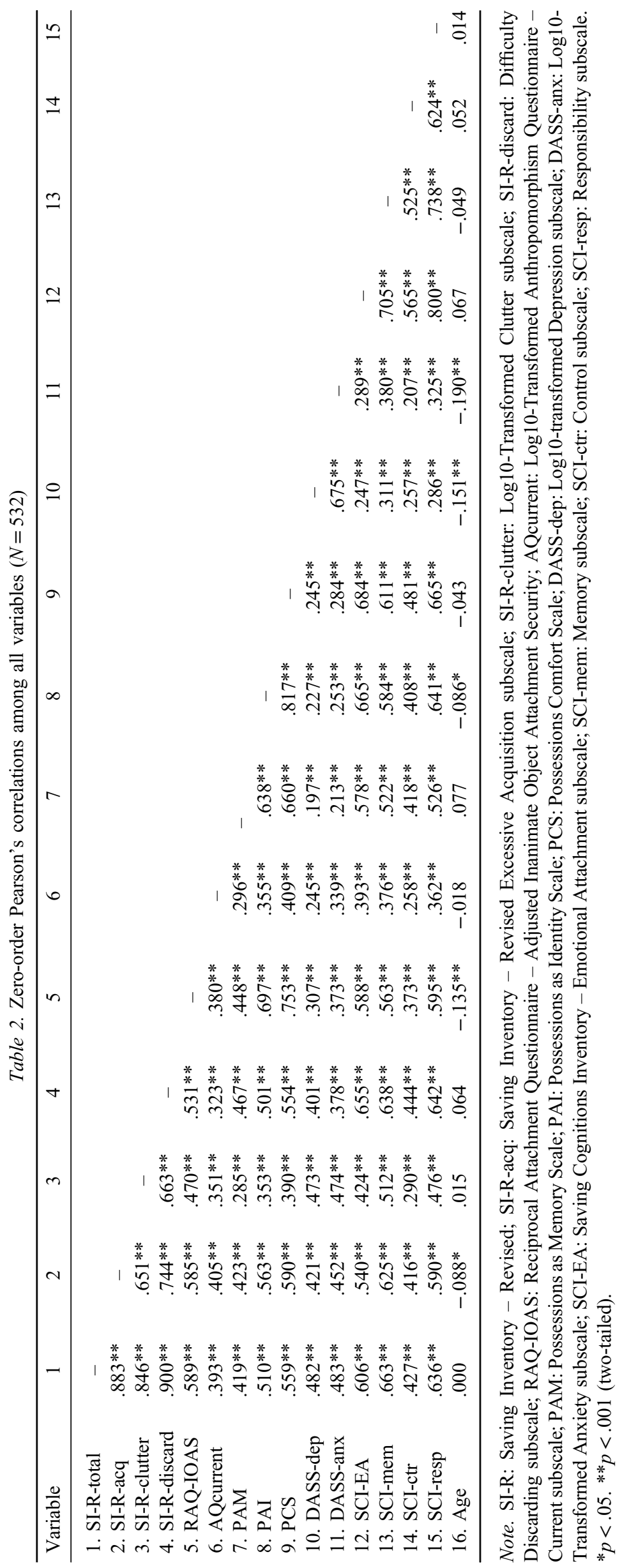


Table 3. Summary of hierarchical regression analysis for variables predicting SI-R-total $(N=532)$

\begin{tabular}{|c|c|c|c|c|c|c|c|c|c|c|}
\hline \multirow[b]{2}{*}{ Variable } & \multicolumn{5}{|c|}{ Model 1} & \multicolumn{5}{|c|}{ Model 2} \\
\hline & $B$ & $S E B$ & $\beta$ & $t$ & $p$ & $B$ & $S E B$ & $\beta$ & $t$ & $p$ \\
\hline DASS-dep & 6.245 & 1.115 & 0.220 & 5.603 & $<.0001$ & 6.106 & 1.085 & 0.216 & 5.627 & $<.0001$ \\
\hline DASS-anx & 3.563 & 1.291 & 0.111 & 2.761 & .006 & 2.197 & 1.288 & 0.068 & 1.705 & .089 \\
\hline SCI-mem & 0.839 & 0.106 & 0.346 & 7.881 & $<.0001$ & 0.711 & 0.108 & 0.293 & 6.600 & $<.0001$ \\
\hline SCI-ctr & -0.052 & 0.116 & -0.017 & -0.447 & .655 & -0.058 & 0.114 & -0.019 & -0.512 & .609 \\
\hline SCI-resp & 0.563 & 0.090 & 0.292 & 6.241 & $<.0001$ & 0.409 & 0.095 & 0.212 & 4.303 & $<.0001$ \\
\hline RAQ-IOAS & & & & & & 0.231 & 0.057 & 0.187 & 4.047 & $<.0001$ \\
\hline AQcurrent & & & & & & 1.815 & 0.949 & 0.061 & 1.913 & .056 \\
\hline PAM & & & & & & 0.005 & 0.072 & 0.003 & 0.071 & .944 \\
\hline PAI & & & & & & -0.065 & 0.071 & -0.048 & -0.918 & .359 \\
\hline \multirow[t]{2}{*}{ PCS } & & & & & & 0.018 & 0.022 & 0.048 & 0.807 & .420 \\
\hline & \multicolumn{5}{|c|}{$R^{2}=.564, F(5,526)=138.27, p<.0001$} & \multicolumn{5}{|c|}{$\Delta R^{2}=.028, \Delta F(5,521)=7.122, p<.0001$} \\
\hline
\end{tabular}

Note. Significant unique contributors to the models are represented in bold. SE: standard error; DASS-dep: Log10-Transformed Depression subscale; DASS-anx: Log10-Transformed Anxiety subscale; SCI-mem: Memory subscale; SCI-ctr: Control subscale; SCI-resp: Responsibility subscale; RAQ-IOAS: Reciprocal Attachment Questionnaire - Adjusted Inanimate Object Attachment Security; AQcurrent: Log10-Transformed Anthropomorphism Questionnaire - Current subscale; PAM: Possessions as Memory Scale; PAI: Possessions as Identity Scale; PCS: Possessions Comfort Scale; SI-R: Saving Inventory - Revised.

Table 4. Summary of hierarchical regression analysis for variables predicting SI-R acquisition $(N=532)$

\begin{tabular}{|c|c|c|c|c|c|c|c|c|c|c|}
\hline \multirow[b]{2}{*}{ Variable } & \multicolumn{5}{|c|}{ Model 1} & \multicolumn{5}{|c|}{ Model 2} \\
\hline & $B$ & $S E B$ & $\beta$ & $t$ & $p$ & $B$ & $S E B$ & $\beta$ & $t$ & $p$ \\
\hline Age & -0.014 & 0.016 & -0.028 & -0.887 & .375 & -0.001 & 0.015 & -0.002 & -0.067 & .947 \\
\hline DASS-dep & 1.248 & 0.378 & 0.142 & 3.303 & .001 & 1.208 & 0.360 & 0.137 & 3.360 & .001 \\
\hline DASS-anx & 1.403 & 0.440 & 0.141 & 3.186 & .002 & 1.032 & 0.429 & 0.103 & 2.403 & .017 \\
\hline SCI-mem & 0.251 & 0.036 & 0.333 & 6.948 & $<.0001$ & 0.188 & 0.036 & 0.250 & 5.273 & $<.0001$ \\
\hline SCI-ctr & 0.026 & 0.039 & 0.027 & 0.656 & .512 & 0.021 & 0.038 & 0.022 & 0.560 & .576 \\
\hline SCI-resp & 0.145 & 0.031 & 0.242 & 4.744 & $<.0001$ & 0.054 & 0.032 & 0.091 & 1.721 & .086 \\
\hline RAQ-IOAS & & & & & & 0.051 & 0.019 & 0.131 & 2.665 & .008 \\
\hline AQcurrent & & & & & & 0.775 & 0.314 & 0.084 & 2.464 & .014 \\
\hline PAM & & & & & & -0.020 & 0.024 & -0.034 & -0.808 & .420 \\
\hline PAI & & & & & & 0.046 & 0.024 & 0.108 & 1.923 & .055 \\
\hline \multirow[t]{2}{*}{ PCS } & & & & & & 0.012 & 0.007 & 0.105 & 1.658 & .098 \\
\hline & \multicolumn{5}{|c|}{$R^{2}=.488, F(5,526)=83.33, p<.0001$} & \multicolumn{5}{|c|}{$\Delta R^{2}=.054, \Delta F(5,520)=12.29, p<.0001$} \\
\hline
\end{tabular}

Note. Significant unique contributors to the models are in bold. SE: standard error; DASS-dep: Log10-Transformed Depression subscale; DASS-anx: Log10-Transformed Anxiety subscale; SCI-mem: Memory subscale; SCI-ctr: Control subscale; SCI-resp: Responsibility subscale; RAQ-IOAS: Reciprocal Attachment Questionnaire - Adjusted Inanimate Object Attachment Security; AQcurrent: Log10Transformed Anthropomorphism Questionnaire - Current subscale; PAM: Possessions as Memory Scale; PAI: Possessions as Identity Scale; PCS: Possessions Comfort Scale; SI-R acquisition: Saving Inventory - Revised Compulsive Acquisition subscale.

for autobiographical memories. Thus, our findings are somewhat convergent with Steketee et al.'s because IOA and the use of possessions for autobiographical memory (PAM) made unique contributions to the final models, whereas PAI and the use of possessions for comfort and safety (PCS) did not.

However, it should be emphasized that PAI and PCS are still important factors to consider in HD because they were highly correlated with hoarding symptoms. The reduction of effects in the final regression model for these facets indicates a mediation effect where IOA fully mediates the relationship between these facets and hoarding. Further studies using longitudinal or experimental designs to examine mediational effects are essential.

\section{Theoretical and clinical implications}

Based on our findings and the extant literature, we propose a tentative extension of the cognitive-behavioral model to explain how specific facets of object attachment affect HD symptoms. First, anthropomorphic tendencies facilitate the formation of attachments to possessions for comfort and safety, particularly when one's sense of self and certainty about safety and security have been compromised, possibly in some cases through early childhood emotional neglect or trauma. Anthropomorphism and IOA then drive compulsive acquisition because the materiality of objects lends a permanence that compensates for the unreliability and unpredictability of human relationships (Norberg et al., 2018). Although hoarding is a compensatory 
Table 5. Summary of hierarchical regression analysis for variables predicting SI-R clutter $(N=532)$

\begin{tabular}{|c|c|c|c|c|c|c|c|c|c|c|}
\hline \multirow[b]{2}{*}{ Variable } & \multicolumn{5}{|c|}{ Model 1} & \multicolumn{5}{|c|}{ Model 2} \\
\hline & $B$ & $S E B$ & $\beta$ & $t$ & $p$ & $B$ & $S E B$ & $\beta$ & $t$ & $p$ \\
\hline DASS-dep & 0.179 & 0.034 & 0.245 & 5.298 & $<.0001$ & 0.176 & 0.033 & 0.241 & 5.299 & $<.0001$ \\
\hline DASS-anx & 0.130 & 0.039 & 0.157 & 3.315 & .001 & 0.088 & 0.039 & 0.107 & 2.234 & .026 \\
\hline SCI-mem & 0.016 & 0.003 & 0.260 & 5.034 & $<.0001$ & 0.014 & 0.003 & 0.231 & 4.369 & $<.0001$ \\
\hline SCI-ctr & -0.006 & 0.004 & -0.071 & -1.617 & .106 & -0.005 & 0.003 & -0.066 & -1.496 & .135 \\
\hline SCI-resp & 0.010 & 0.003 & 0.207 & 3.768 & $<.0001$ & 0.009 & 0.003 & 0.173 & 2.956 & .003 \\
\hline RAQ-IOAS & & & & & & 0.007 & 0.002 & 0.206 & 3.761 & $<.0001$ \\
\hline AQcurrent & & & & & & 0.073 & 0.029 & 0.095 & 2.519 & .012 \\
\hline PAM & & & & & & 0.000 & 0.002 & -0.007 & -0.157 & .875 \\
\hline PAI & & & & & & -0.003 & 0.002 & -0.083 & -1.342 & .180 \\
\hline \multirow[t]{2}{*}{ PCS } & \multirow{2}{*}{\multicolumn{5}{|c|}{$R^{2}=.410, F(5,526)=73.17, p<.001$}} & 0.000 & 0.001 & -0.045 & -0.644 & .520 \\
\hline & & & & & & \multicolumn{5}{|c|}{$\Delta R^{2}=.04, \Delta F(5,521)=6.61, p<.001$} \\
\hline
\end{tabular}

Note. Significant unique contributors to the model are in bold. SE: standard error; DASS-dep: Log10-Transformed Depression subscale; DASS-anx: Log10-Transformed Anxiety subscale; SCI-mem: Memory subscale; SCI-ctr: Control subscale; SCI-resp: Responsibility subscale; RAQ-IOAS: Reciprocal Attachment Questionnaire - Adjusted Inanimate Object Attachment Security; AQcurrent: Log10Transformed Anthropomorphism Questionnaire - Current subscale, PAM: Possessions as Memory Scale; PAI: Possessions as Identity Scale; PCS: Possessions Comfort Scale; SI-R Clutter: Log10-Transformed Saving Inventory - Revised Clutter subscale.

Table 6. Summary of hierarchical regression analysis for variables predicting SI-R discard $(N=532)$

\begin{tabular}{|c|c|c|c|c|c|c|c|c|c|c|}
\hline \multirow[b]{2}{*}{ Variable } & \multicolumn{5}{|c|}{ Model 1} & \multicolumn{5}{|c|}{ Model 2} \\
\hline & $B$ & $S E B$ & $\beta$ & $t$ & $p$ & $B$ & $S E B$ & $\beta$ & $t$ & $p$ \\
\hline DASS-dep & 1.928 & 0.423 & 0.192 & 4.563 & $<.0001$ & 1.890 & 0.417 & 0.188 & 4.536 & $<.0001$ \\
\hline DASS-anx & 0.175 & 0.489 & 0.015 & 0.357 & .721 & -0.053 & 0.495 & -0.005 & -0.106 & .915 \\
\hline SCI-mem & 0.270 & 0.040 & 0.313 & 6.680 & $<.0001$ & 0.223 & 0.041 & 0.259 & 5.397 & $<.0001$ \\
\hline SCI-ctr & 0.015 & 0.044 & 0.014 & 0.349 & .727 & -0.002 & 0.044 & -0.002 & -0.045 & .964 \\
\hline SCI-resp & 0.235 & 0.034 & 0.342 & 6.862 & $<.0001$ & 0.188 & 0.036 & 0.275 & 5.161 & $<.0001$ \\
\hline RAQ-IOAS & & & & & & 0.050 & 0.022 & 0.114 & 2.279 & .023 \\
\hline AQcurrent & & & & & & 0.049 & 0.364 & 0.005 & 0.134 & .893 \\
\hline PAM & & & & & & 0.060 & 0.028 & 0.093 & 2.182 & .030 \\
\hline PAI & & & & & & -0.035 & 0.027 & -0.073 & -1.296 & .195 \\
\hline \multirow[t]{2}{*}{ PCS } & & & & & & 0.011 & 0.009 & 0.080 & 1.250 & .212 \\
\hline & \multicolumn{5}{|c|}{$R^{2}=.508, F(5,526)=108.67, p<.0001$} & \multicolumn{5}{|c|}{$\Delta R^{2}=.019, \Delta F(5,521)=4.28, p<.0001$} \\
\hline
\end{tabular}

Note. Significant unique contributors to the final model are represented in bold. SE: standard error; DASS-dep: Log10-Transformed Depression subscale; DASS-anx: Log10-Transformed Anxiety subscale; SCI-mem: Memory subscale; SCI-ctr: Control subscale; SCI-resp: Responsibility subscale; RAQ-IOAS: Reciprocal Attachment Questionnaire - Adjusted Inanimate Object Attachment Security; AQcurrent: Log10-Transformed Anthropomorphism Questionnaire - Current subscale; PAM: Possessions as Memory Scale; PAI: Possessions as Identity Scale; PCS: Possessions Comfort Scale; SI-R-discard: Saving Inventory - Revised Difficulty Discarding subscale.

attempt to find safety and security, the objects paradoxically become a source of anxiety and insecurity. Combined with the threat to the autobiographical self, these feelings of insecurity become aversive and lead to indiscriminate saving and hoarding beliefs. The objects never truly satisfy the person's need for safety but instead serve to reinforce hoarding beliefs and a need to assuage their fears with even more things. Unable to regulate their emotions, these individuals persist with and rely on hoarding, which might sooth negative emotions in the short term, but becomes counterproductive in the long run (Grisham, Martyn, Kerin, Baldwin, \& Norberg, 2018).

\section{Limitations and implications for further research}

The proposed extension to the cognitive-behavioral model posits that the facets of object attachment result in hoarding. However, no causal conclusions can be made in this study due to its cross-sectional and correlational design. Experimental research examining the causal effects of IOA is required and would provide a stronger rationale for the development and testing of interventions to reduce this facet of object attachment. In addition, the use of an online community sample limits generalizability of our findings to a clinical population. Further research with a clinical sample with diagnoses confirmed using structured clinical interviews are required. Although this study relied on online data collection via MTurk, concerns regarding data quality were mitigated by careful screening of data for valid responses.

\section{CONCLUSIONS}

Our proposed compensatory model of object attachment as an extension of the cognitive-behavioral model of HD is in 
line with other compensatory models for behavioral addictions (e.g., Kardefelt-Winther, 2014). The model requires further evaluation and given that IOA had the strongest and most consistent link with hoarding symptoms, further research into this facet is critical. Further research into anthropomorphism and the use of possessions for autobiographical memory are also warranted. Assisting sufferers to increase a sense of security to specific objects that are linked to important autobiographical memories (akin to transitional objects) might facilitate discarding of other items and reduce indiscriminate attachment to possessions. Alternatively, helping HD sufferers build more secure interpersonal attachments that might reduce anthropomorphism and the need for compulsive acquisition and indiscriminate saving of objects as compensatory strategies.

Funding sources: This research was supported by an Australian Government Research Training Program Scholarship for $\mathrm{KY}$.

Authors' contribution: Both authors made substantial contributions to the conception, design, data collection, and analysis and interpretation of data. The manuscript was drafted by KY with critical revisions by JRG. Both authors gave final approval of the version to be submitted and any revised version.

Conflict of interest: The authors are not aware of any actual, perceived, or potential conflict of interests.

\section{REFERENCES}

American Psychiatric Association [APA]. (2000). Diagnostic and statistical manual of mental disorders (4th ed., text rev.). Washington, DC: American Psychiatric Association.

American Psychiatric Association [APA]. (2013). Diagnostic and statistical manual of mental disorders (5th ed.). Arlington, VA: American Psychiatric Association.

Arditte, K. A., Çek, D., Shaw, A. M., \& Timpano, K. R. (2016). The importance of assessing clinical phenomena in Mechanical Turk research. Psychological Assessment, 28(6), 684-691. doi: $10.1037 /$ pas0000217

Bratiotis, C., Steketee, G., Davidow, J., Samuels, J., Tolin, D., \& Frost, R. O. (2013). Use of services by people who hoard objects. Best Practices in Mental Health: An International Journal, 9(2), 39-51.

Brown, T. A., Chorpita, B. F., Korotitsch, W., \& Barlow, D. H. (1997). Psychometric properties of the Depression Anxiety Stress Scales (DASS) in clinical samples. Behaviour Research and Therapy, 35(1), 79-89. doi:10.1016/S0005-7967(96)00068-X

Burgess, A. M., Graves, L. M., \& Frost, R. O. (2018). My possessions need me: Anthropomorphism and hoarding. Scandinavian Journal of Psychology, 59(3), 340-348. doi:10.1111/sjop. 12441

Chandler, J., \& Shapiro, D. (2016). Conducting clinical research using crowdsourced convenience samples. Annual Review of Clinical Psychology, 12(1), 53-81. doi:10.1146/annurevclinpsy-021815-093623
Cherrier, H., \& Ponnor, T. (2010). A study of hoarding behavior and attachment to material possessions. Qualitative Market Research: An International Journal, 13(1), 8-23. doi:10.1108/ 13522751011013945

Coles, M. E., Frost, R. O., Heimberg, R. G., \& Steketee, G. (2003). Hoarding behaviors in a large college sample. Behaviour Research and Therapy, 41(2), 179-194. doi:10.1016/S00057967(01)00136-X

Conway, M. A., Singer, J. A., \& Tagini, A. (2004). The self and autobiographical memory: Correspondence and coherence. Social Cognition, 22(5), 491-529. doi:10.1521/soco.22.5. 491.50768

Cromer, K. R., Schmidt, N. B., \& Murphy, D. L. (2007). Do traumatic events influence the clinical expression of compulsive hoarding? Behaviour Research and Therapy, 45(11), 2581-2592. doi:10.1016/j.brat.2007.06.005

Csikszentmihalyi, M., \& Rochberg-Halton, E. (1981). The meaning of things: Domestic symbols and the self. Cambridge, UK: Cambridge University Press.

Dozier, M. E., Taylor, C. T., Castriotta, N., Mayes, T. L., \& Ayers, C. R. (2017). A preliminary investigation of the measurement of object interconnectedness in hoarding disorder. Cognitive Therapy and Research, 41(5), 799-805. doi:10.1007/s10608017-9845-x

Epley, N., Waytz, A., Akalis, S., \& Cacioppo, J. T. (2008). When we need a human: Motivational determinants of anthropomorphism. Social Cognition, 26(2), 143-155. doi:10.1521/soco.2008. 26.2.143

Fortuna, K., Baor, L., Israel, S., Abadi, A., \& Knafo, A. (2014). Attachment to inanimate objects and early childcare: A twin study. Frontiers in Psychology, 5, 486. doi:10.3389/fpsyg.2014.00486

Frost, R. O., Gabrielson, I., Deady, S., Dernbach, K. B., Guevara, G., Peebles-Dorin, M., Yap, K., \& Grisham, J. R. (2018). Scrupulosity and hoarding. Comprehensive Psychiatry, 86, 19-24. doi:10.1016/j.comppsych.2018.06.011

Frost, R. O., \& Hartl, T. L. (1996). A cognitive-behavioral model of compulsive hoarding. Behaviour Research and Therapy, 34(4), 341-350. doi:10.1016/0005-7967(95)00071-2

Frost, R. O., Hartl, T. L., Christian, R., \& Williams, N. (1995). The value of possessions in compulsive hoarding: Patterns of use and attachment. Behaviour Research and Therapy, 33(8), 897-902. doi:10.1016/0005-7967(95)00043-W

Frost, R. O., \& Hristova, V. (2011). Assessment of hoarding. Journal of Clinical Psychology, 67(5), 456-466. doi:10.1002/ jclp. 20790

Frost, R. O., Steketee, G., \& Grisham, J. (2004). Measurement of compulsive hoarding: Saving Inventory - Revised. Behaviour Research and Therapy, 42(10), 1163-1182. doi:10.1016/ j.brat.2003.07.006

Frost, R. O., Steketee, G., Tolin, D. F., Sinopoli, N., \& Ruby, D. (2015). Motives for acquiring and saving in hoarding disorder, OCD, and community controls. Journal of ObsessiveCompulsive and Related Disorders, 4, 54-59. doi:10.1016/ j.jocrd.2014.12.006

Furby, L. (1978). Possession in humans: An exploratory study of its meaning and motivation. Social Behavior and Personality, 6(1), 49-65. doi:10.2224/sbp.1978.6.1.49

Grisham, J. R., Frost, R. O., Steketee, G., Kim, H.-J., Tarkoff, A., \& Hood, S. (2009). Formation of attachment to possessions in compulsive hoarding. Journal of Anxiety Disorders, 23(3), 357-361. doi:10.1016/j.janxdis.2008.12.006 
Grisham, J. R., Martyn, C., Kerin, F., Baldwin, P. A., \& Norberg, M. M. (2018). Interpersonal functioning in hoarding disorder: An examination of attachment styles and emotion regulation in response to interpersonal stress. Journal of ObsessiveCompulsive and Related Disorders, 16, 43-49. doi:10.1016/ j.jocrd.2017.12.001

Grisham, J. R., Steketee, G., \& Frost, R. O. (2008). Interpersonal problems and emotional intelligence in compulsive hoarding. Depression and Anxiety, 25(9), E63-E71. doi:10.1002/da. 20327

Grisham, J. R., Williams, A. D., \& Kadib, R. (2010). Hoarding as a behavioral addiction. In B. A. Johnson (Ed.), Addiction medicine: Science and practice (Vol. 1, pp. 687-703). New York, NY: Springer.

Hartl, T. L., Duffany, S. R., Allen, G. J., Steketee, G., \& Frost, R. O. (2005). Relationships among compulsive hoarding, trauma, and attention-deficit/hyperactivity disorder. Behaviour Research and Therapy, 43(2), 269-276. doi:10.1016/j.brat. 2004.02.002

Kardefelt-Winther, D. (2014). A conceptual and methodological critique of Internet addiction research: Towards a model of compensatory Internet use. Computers in Human Behavior, 31, 351-354. doi:10.1016/j.chb.2013.10.059

Kellett, S., Greenhalgh, R., Beail, N., \& Ridgway, N. (2010). Compulsive hoarding: An interpretative phenomenological analysis. Behavioural and Cognitive Psychotherapy, 38(2), 141-155. doi:10.1017/S1352465809990622

Kellett, S., \& Holden, K. (2014). Emotional attachment to objects in hoarding: A critical review of the evidence. In R. O. Frost \& G. Steketee (Eds.), The Oxford handbook of hoarding and acquiring (pp. 120-138). New York, NY: Oxford University Press.

Kings, C. A., Knight, T., \& Moulding, R. (2018). Using photoelicitation and interpretative phenomenological analysis to explore possessions as links to self-concept and the identities of others in hoarding disorder. Psychology and Psychotherapy: Theory, Research and Practice. Advance online publication. doi:10.1111/papt.12211

Kings, C. A., Moulding, R., \& Knight, T. (2017). You are what you own: Reviewing the link between possessions, emotional attachment, and the self-concept in hoarding disorder. Journal of Obsessive-Compulsive and Related Disorders, 14, 51-58. doi:10.1016/j.jocrd.2017.05.005

Kyrios, M., Mogan, C., Moulding, R., Frost, R. O., Yap, K., \& Fassnacht, D. B. (2018). The cognitive-behavioural model of hoarding disorder: Evidence from clinical and non-clinical cohorts. Clinical Psychology \& Psychotherapy, 25(2), 311-321. doi:10.1002/cpp.2164

Lovibond, S. H., \& Lovibond, P. F. (1995). Manual for the Depression Anxiety Stress Scales (2nd ed.). Sydney, Australia: Psychology Foundation.

Miller, D. (2008). The comfort of things. Cambridge, UK: Polity Press.

Mogan, C., Kyrios, M., Schweitzer, I., Yap, K., \& Moulding, R. (2012). Phenomenology of hoarding - What is hoarded by individuals with hoarding disorder? Journal of ObsessiveCompulsive and Related Disorders, 1(4), 306-311. doi:10.1016/j.jocrd.2012.08.002

Neave, N., Jackson, R., Saxton, T., \& Hönekopp, J. (2015). The influence of anthropomorphic tendencies on human hoarding behaviours. Personality and Individual Differences, 72, 214-219. doi:10.1016/j.paid.2014.08.041

Neave, N., Tyson, H., McInnes, L., \& Hamilton, C. (2016). The role of attachment style and anthropomorphism in predicting hoarding behaviours in a non-clinical sample. Personality and Individual Differences, 99, 33-37. doi:10.1016/j.paid.2016. 04.067

Nedelisky, A., \& Steele, M. (2009). Attachment to people and to objects in obsessive-compulsive disorder: An exploratory comparison of hoarders and non-hoarders. Attachment \& Human Development, 11(4), 365-383. doi:10.1080/14616730 903016987

Norberg, M. M., Crone, C., Kwok, C., \& Grisham, J. R. (2018). Anxious attachment and excessive acquisition: The mediating roles of anthropomorphism and distress intolerance. Journal of Behavioral Addictions, 7(1), 171-180. doi:10.1556/2006.7. 2018.08

Pertusa, A., Fullana, M. A., Singh, S., Alonso, P., Menchon, J. M., \& Mataix-Cols, D. (2008). Compulsive hoarding: OCD symptom, distinct clinical syndrome, or both? The American Journal of Psychiatry, 165(10), 1289-1298. doi:10.1176/ appi.ajp.2008.07111730

Przeworski, A., Cain, N., \& Dunbeck, K. (2014). Traumatic life events in individuals with hoarding symptoms, obsessivecompulsive symptoms, and comorbid obsessive-compulsive and hoarding symptoms. Journal of Obsessive-Compulsive and Related Disorders, 3(1), 52-59. doi:10.1016/j.jocrd. 2013.12.002

Roster, C. A. (2015). "Help, I have too much stuff!": Extreme possession attachment and professional organizers. Journal of Consumer Affairs, 49(2), 303-327. doi:10.1111/joca.12052

Steketee, G., Frost, R. O., \& Kyrios, M. (2003). Cognitive aspects of compulsive hoarding. Cognitive Therapy and Research, 27(4), 463-479. doi:10.1023/A:1025428631552

Timpano, K. R., \& Shaw, A. M. (2013). Conferring humanness: The role of anthropomorphism in hoarding. Personality and Individual Differences, 54(3), 383-388. doi:10.1016/j.paid. 2012.10.007

Wang, Q., Lee, D., \& Hou, Y. (2017). Externalising the autobiographical self: Sharing personal memories online facilitated memory retention. Memory, 25(6), 772-776. doi:10.1080/ 09658211.2016.1221115

Winnicott, D. W. (1953). Transitional objects and transitional phenomena; a study of the first not-me possession. International Journal of Psychoanalysis, 34(2), 89-97.

Yap, K., \& Grisham, J. R. (2018, October). The development and validation of the Possessions as Memories and Self-Extensions Scale. Paper presented at Poster session presented at the 39th National Conference of the Australian Association for Cognitive and Behaviour Therapy, Brisbane, Australia. 